\title{
The effect of anthocyanin consumption on blood and tissue levels of fatty acids in animals and humans
}

\author{
C. O’Neill, D. Vauzour, A. Cassidy and A. M. Minihane \\ Nutrition Department, Norwich Medical School, University of East Anglia, Norwich NR4 7TJ, UK
}

Anthocyanins (ACNs) are part of a phenolic group of compounds known as flavonoids; they are responsible for the red and purple colours of many plant based foods, for example blackcurrants, blueberries and blackberries which are major dietary sources of ACNs in the diet, along with red wine. It has previously been reported that red wine drinkers have higher levels of the $n$ - 3 fatty acids, eicosapentaenoic acid (EPA) and docosahexaenoic acid (DHA) in their blood and cells ${ }^{(1)}$. In 2010 a study in rats showed that ACNs have the potential to increase plasma EPA and DHA levels ${ }^{(2)}$, attributed to their increased bioconversion from $\alpha$-Linolenic acid (ALNA) into EPA and DHA. This project aimed to further investigate the impact of dietary ACNs on $n-3$ fatty acid concentrations and bioconversion in stored samples from a human and two rodent studies.

Plasma samples were acquired from a study in which 26 healthy postmenopausal women had consumed $500 \mathrm{mg} / \mathrm{d}$ ACNs as cyanidin glycosides (from elderberry) or placebo for 12 weeks. Serum, cortex, heart and muscle tissue samples were obtained from a study in which rats were fed a control diet, or a diet supplemented with either $2 \%$ (w/w) blueberry, $320 \mu \mathrm{g}$ ACN extract/g feed or $80 \mu \mathrm{g}$ flavanols/g feed for 6 weeks. Serum and liver samples were also analysed from a study in which rats were fed a diet supplemented with one of the following four for 8 weeks: Palm oil, Palm oil $+\mathrm{ACN}(240 \mathrm{mg} / \mathrm{Kg}$ feed), Rapeseed oil, or Rapeseed oil $+\mathrm{ACN}(240 \mathrm{mg} / \mathrm{Kg}$ feed). Fatty acid levels were analysed using GC-FID. The data was analysed using by 2-way ANOVA, followed by a Bonferroni's multiple comparison test.

As shown in Figure 1, ACN consumption in post-menopausal women had no significant effect on plasma levels of various fatty acids, including EPA and DHA. In addition, fatty acid analysis of the serum, liver, cortex, heart and muscle tissue samples from the two rodent studies showed that consumption of ACN had no significant effect on levels of EPA and DHA (data not shown).
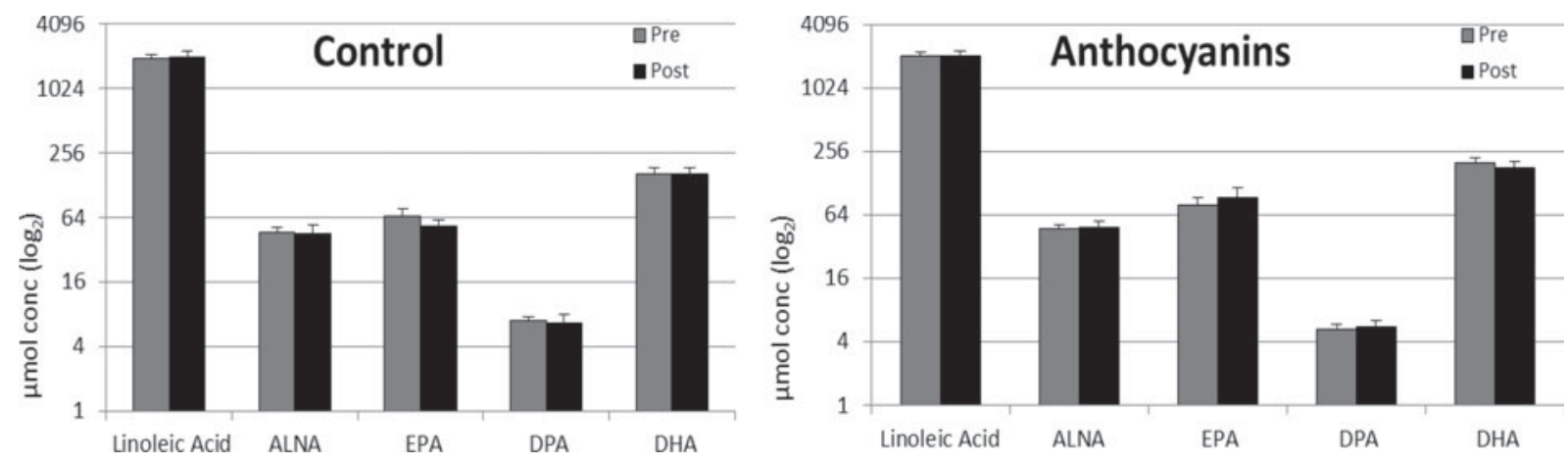

Fig. 1. Levels of fatty acids in plasma samples from post-menopausal women (mean $\pm \mathrm{SE})$.

Contrary to the rodent study conducted in 2010, this project has shown that consumption of ACNs does not stimulate fatty acid pathways to produce increased tissue levels of EPA and DHA and it may be speculated that some other component is responsible for the improved EPA and DHA status in red wine consumers.

1. di Giuseppe R. et al. (2009) Alcohol consumption and n-3 polyunsaturated fatty acids in healthy men and women from 3 European populations. AJCN. 2. Toufektsian M.-C. et al. (2010) Dietary Flavonoids Increase Plasma Very Long-Chain (n-3) Fatty Acids in Rats. JN. 